Environment Conservation Journal 20 (1\&2) 139-142, 2019

ISSN 0972-3099 (Print) 2278-5124 (Online)

Abstracted and Indexed

\title{
Size-group related variation in the feeding behaviour of an ornamental fish, Puntius conchonius from Mandal river system in Central Himalaya region of Garhwal, India.
}

\author{
Bahuguna P. ${ }^{1} \bowtie$ and Baluni P. ${ }^{2}$
}

Received: 29.10.2018

Revised: 28.02 .2019

Accepted: 14.05.2019

\begin{abstract}
The present work deals with the study of food and feeding habit of $P$. conchonious an ornamental fish of hill streams of Garhwal Himalaya. The gut content of fishes of various size and age groups were analyzed. It was observed that with the increase in size the preference for food changed. From the initial nature of being a carnivore it later on shifted towards herbivory with preference for algal matter. The study of this shifting food preference of fish will help in the management of the aquarium.
\end{abstract}

Key words: Size group, Ornamental fish, Puntius conchonius, Mandal River.

\section{Introduction}

Food is the main source of energy and plays a vital role in determining population levels, rate of growth and condition of fishes. Studies on food and feeding habits of fish help to determine the niche of fises in the ecosystem, preferred food items of the fishes and also to reveal the food spectrum overlapping with that of co-existing fishes (Basudha and Vishwanath, 1999). The knowledge of food and feeding habits helps in selecting the species of fishes for culture that would produce optimum yield by utilizing all the available potential resource in the water bodies. Plenty of research work has been done on the food and feeding habits of freshwater fishes. Some of the significant contributors in these types of researches are Pillay (1953), Sharma (1984), Dobriyal and Negi (1998), Thapliyal et al., (2004), Mondal et al., (2005) and Sharma et al., (2018). The aim of the study was to investigate the type of food eaten by Puntius conchonius. Such studies could be important in the rational management and culture of the commercially important freshwater fish.

\section{Author's Address}

${ }^{1}$ Fish Biology and Aquatic biodiversity Laboratory, Department of Zoology, Agustyamuni - 246421, Uttarakhand, India

${ }^{2}$ Ecology lab, Department of Botany, A.P.B. Govt. P.G.College College Agustyamuni - 246421, Uttarakhand, India

(E-mail: pratibaluni@gmail.com)

E-mail.: pankajpaurii@gmail.com

\section{Materials and Methods}

The gut contents were removed and preserved in 4 $\%$ formalin solution. The food was analyzed qualitatively on point method basis that is the qualitative analysis was made and points were given purely on the basis of observation. Various food items were identified with the help of Ward and Whipple (1959), Needham and Needham (1962) and Prescott (1939a,b). The preserved food items were mounted on slides and each food items was observed under the microscope.

\section{Results and Discussion}

The food and feeding habits of fish is undoubtedly an important aspect in the biology and ecological study of fishes. Fish biologists all over the world agree that fishes are herbivorous, carnivorous and omnivorous. However, besides the three primary groups, fishes are further divided into several sub groups on the basis of nature of food consumed by them. In case of herbivorous the plant matter contains not less than $75 \%$ of the average annual food (Das and Moitra, 1963). This group is further divided in to planktophagus and the detritophagus depending upon whether they feed on plankton (Silver carp and Catla) or detritus (Tor chelynoides). Nikolsky (1963) suggested another classification of fish based on amount of variation 


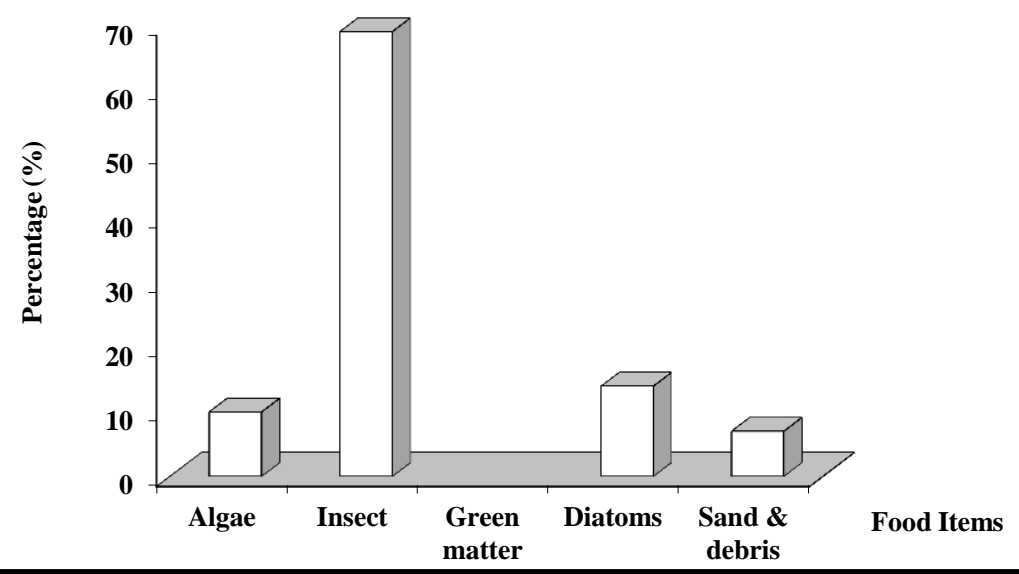

Fig 1. Percentage of different Food Items in size group 2.5 - 3.5 of $P$. conchonius (Ham.-Buch.)

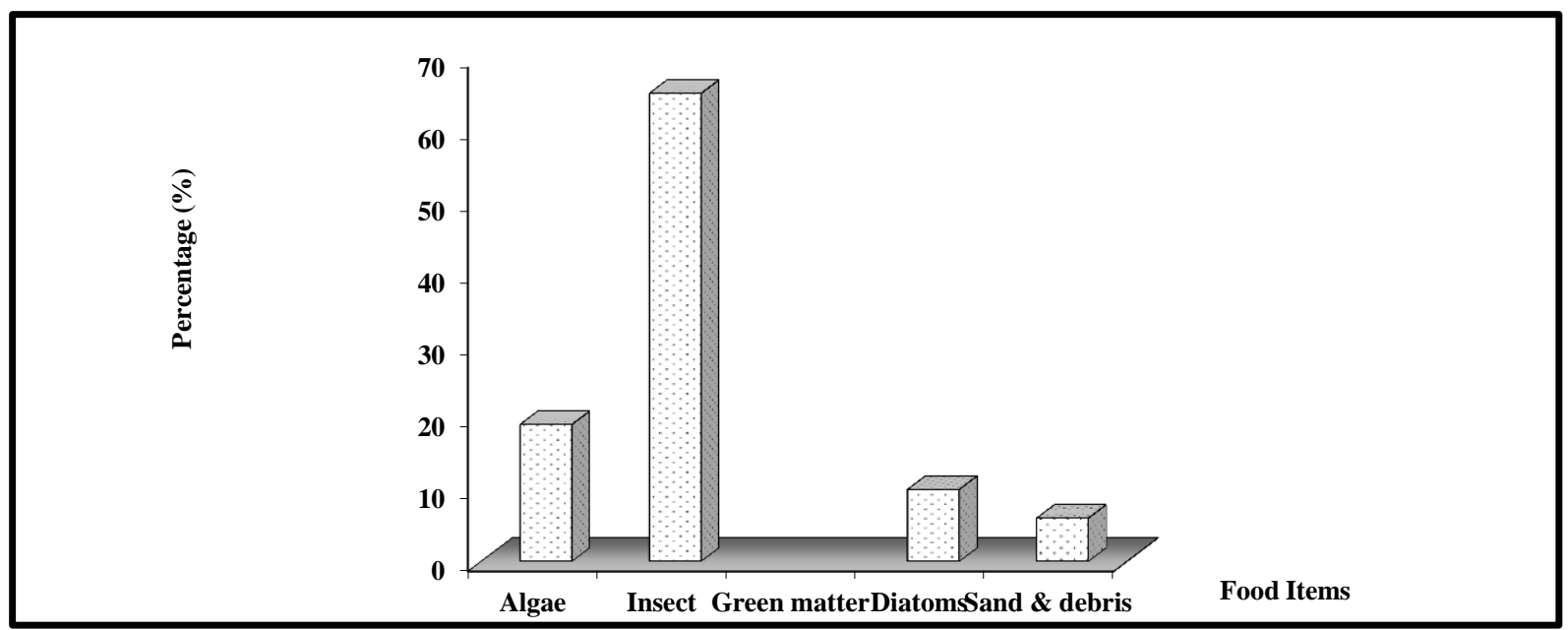

Fig 2. Percentage of different Food Items in size group 3.6 - 4.5 of $P$. conchonius (Ham.-Buch.)

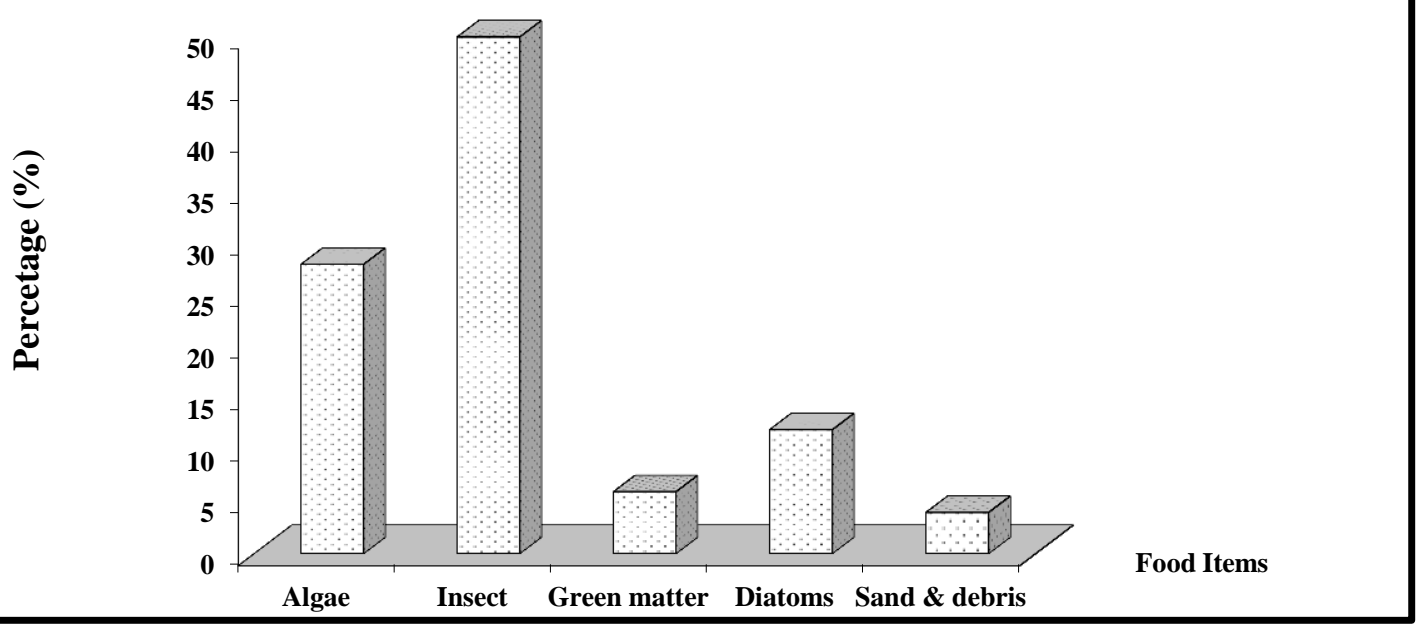

Fig 3. Percentage of different Food Items in size group 4.6 - 5.5 of $P$. conchonius (Ham.-Buch.) 


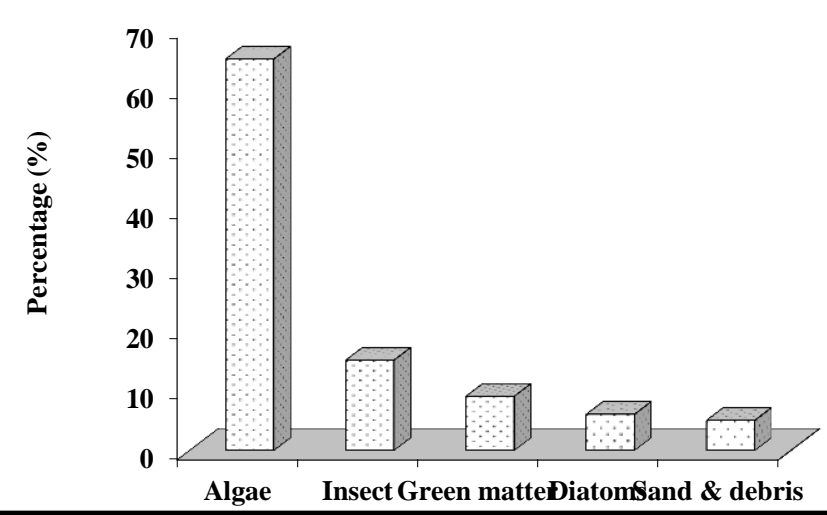

Food Items

Algae Insect Green matteĐiatomsand \& debris

Fig: 4. Percentage of different Food Items in size group 5.6 - 6.5 of P. conchonius (Ham.-Buch.)

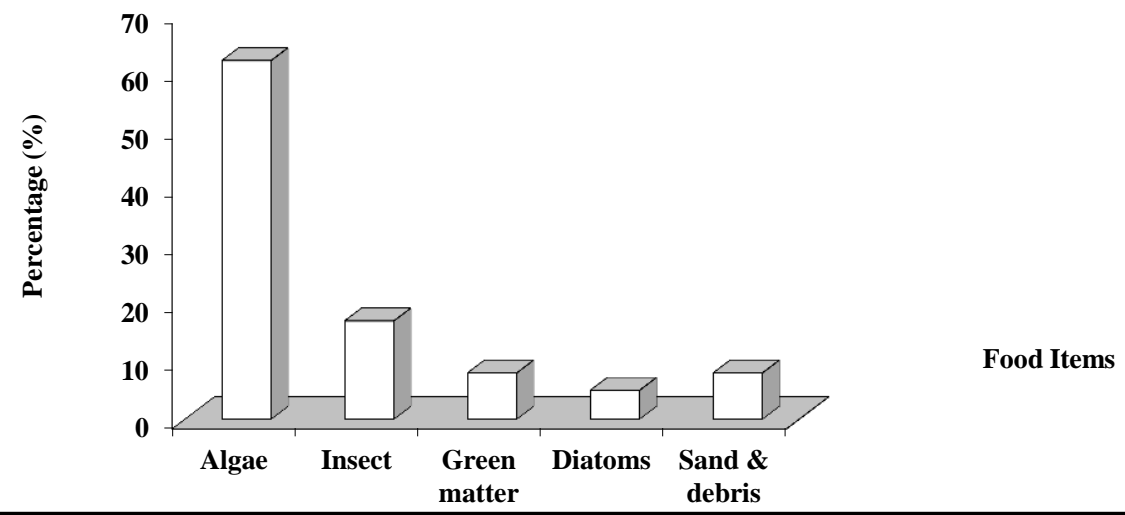

Fig 5. Percentage of different Food Items in size group 6.6 -7.5 of P. conchonius (Ham.-Buch.)

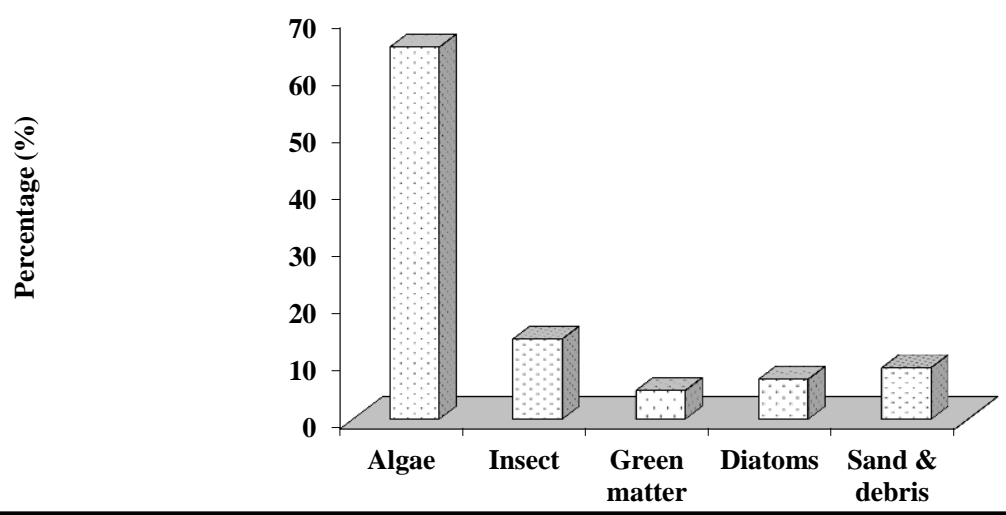

Food Items

Fig 6. Percentage of different Food Items in size group 7.6 - 8.5 of P. conchonius (Ham.-Buch.)

in the types of food eaten by them. Thus, the fishes single type of food). Nikolsky (op.cit.) also are either (a) euryphagic (feeding on a variety of classified the food of fish into (a) basic food foods), (b) Stenophagic (feeding on a few different (comprise the main part of the total food intake), types of food) or (c) monophagic (feeding on only a (b) secondary food (frequently found in the gut 


\section{Bahuguna and Baluni}

contents, but in small amounts), (c) incidental food (rarely found in the gut contents) and (d) emergency food (the fish consumes when the basic food is not available).

The present work on the feeding biology of $P$. conchonius has revealed that it is a herbiomnivorous fish as it consumes more green matter than the insects. The primary food mainly constituted of green and blue-green algae. The secondary food preferences of this fish were the insects as they were frequently found in the gastrointestinal tract or alimentary canal. The diatoms were also present in the gut contents, which may be called incidental food because diatoms are attached with the periphytic algae. The percentages of different food items in different size groups are shown in Figure 1.1 to 1.7. Size-group related variation in the feeding behaviour of an ornamental fish Puntius conchonius from Mandal River showed that fishes with size ranging from 2.5 to $5.5 \mathrm{~mm}$ were mostly carnivores in feeding behaviour whereas those in 5.6 to $8.5 \mathrm{~mm}$ range were having preference for herbivory.

It was observed that the smaller size group fishes preferred insect's food. When the fish size increased, their preference shifted towards the algal food matter. Change of food habits with increase in size has been reported for many cyprinids species. Thus, with increase in size, $B$. dorsalis and $B$. amphibius, change their diet from one of predominantly crustaceans to one of predominantly higher plants (De Silva et al., 1980).

\section{Conclusion}

Puntius conchonius is an important fresh water fish species of Garhwal Himalaya. Size group related variation in the feeding showed that fishes with size ranging from 2.5 to $5.5 \mathrm{~mm}$ were mostly carnivores and preferred insects as food whereas those from 5.6 to $8.5 \mathrm{~mm}$ ranged showed preference fro algal matter. The study of this shifting food preference of fish help in the management of the aquarium.

\section{References}

Basudha,C. H. and Vishwanath, W. 1999. Food and feeding habits of an endemic carp Osteo brand belongori (Val.) in Manipur. Indian J. Fish. 46(1): 71-77.
Das, S. M. and Moitra, S. K. 1963. Studies on the food and feeding habits of some fresh water fishes of India-IV: A review on the food and habits with general conclusion. Icthyology-III, 2(1-2):107-115.

De Silva, S. S., Cumaranatunga, P. R. T. and De Silva, C. D. 1980. Food, feeding ecology and morphological features associated with feeding of four co-occurring cyprinids (Pisces: Cyprinidae). Neth. J. Zool. 30: 54-73.

Dobriyal, A. K. and Negi, K. S. 1998. Food analysis of a hill stream cat fish Glyptothorax madraspatanum (Day) in the river Nayar of Garhwal Himalaya. Bioved (2) : 147-150.

Mandal, M. R., Dewan, S., Hossain, M. A. Asaduzzaman, M., Islam, M. A. and Rozario, U. A. 2005. Food and feeding habits of Puntius ganionotus (Thai Sarpunti) in Rice field. Pak. J. Biol. Sci., 8 (3) : 386-395.

Needham J. G. and Needham P. R. 1962. A guide to freshwater biology. Holden Day Ins., San Francisco (USA). 108.

Nikolsky, G. V. 1963. The ecology of fishes. Academic Press London and Newyork: 352

Pillay, T. V. R. 1953. Study on the food, feeding habits and alimentary tract of Gray mullet, Mugil tade (Forsk). Proc. Nat. Inst. Sci. India, 19 : 777-827.

Prescott, G. W. 1939a. How to know the fresh water Algae. Brown Co. publishers. 450pp

Prescott, G. W. 1939b. Some relationship of phytoplankton to limnology and aquatic biology. Publ. Amer. Asso. Adv. Sci., 10: 65-78.Service New Delhi.

Sharma, A. K. 2018. Food and Feeding Habits of Schizothorox Richardsonii (Gray, 1832) Inhibiting Bhagirathi River, Tehri Garhwal, India. Int. J. Recent Sci. Res. 9(4): 255622556.

Sharma, R. C. 1984. Quality and quantitative seasonal variation in feeding of snow trout Schizothorax plagiostomus (Heckel) of Garhwal Himalaya. Biological Bulletin of India. $6: 20-25$.

Thapliyal, A., Dobriyal, A. K., Joshi, H. K. and Bisht, K. L. 2004. Food analysis and factors responsible for feeding intensity in the hill stream catfish Pseudecheneis sulcatus (Mc Clelland). Aquacult 5(2) : 179-187

Ward, H. B. and Whipple, G. V. 1966. Fresh water biology. John wiley and sons, Inc., New York. 